\title{
A retrospective comparative series comparing monarc and sparc suburethral slings ${ }^{* \#}$
}

\author{
Andrew Foote \\ Calvary Hospital, Canberra, Australia \\ Email: ajfoote@netspeed.com.au
}

Received 7 July 2013; revised 6 August 2013; accepted 14 August 2013

Copyright (C 2013 Andrew Foote. This is an open access article distributed under the Creative Commons Attribution License, which permits unrestricted use, distribution, and reproduction in any medium, provided the original work is properly cited.

\begin{abstract}
A Retrospective Comparative Series Comparing Monarc and Sparc Suburethral Slings. Introduction and Hypothesis: There are a number of suburethral slings used in current practice to treat female urinary incontinence. To date there has been a lack of larger comparative series. This paper aims to evaluate the effectiveness and complications of two types of suburethral sling. Methods: A retrospective comparative series comparing 113 consecutive Sparcsuburethral slings with 112 consecutive Monarc slings. Results: The success rate of SparcvsMonarc was similar at 6 weeks $(96.1 \%$ vs $94.2 \%$, NS) and at 6 months $(96.0 \%$ vs $92.6 \%$, NS). The Monarc procedure had less intraoperative bladder fenestrations \& less postoperative urgency. Conclusions: Both procedures had a similar success rate, while the Monarc had less complications. Brief Summary: Both procedures had a similar success rate, while the Monarc had less complications of intraoperative bladder fenestration \& postoperative urgency.
\end{abstract}

Keywords: Case Control Series; Female Urinary Incontinence; Suburethral Sling

\section{INTRODUCTION}

Female stress urinary incontinence is defined as the involuntary loss of urine on effort or physical exertion. Prior to the 1990s, surgical treatment was a major procedure, performed via a significant lower abdominal skin incision and the placement of bladder elevating sutures or a fascial sling under the urethra. The minimally invasive synthetic retropubic suburethral sling was first described in 1995 [1]. A subsequent randomised trial with Burch colposuspension found that the procedure was

*Financial Disclaimer/Conflict of Interest: None.

"Disclosure: There are no interests to disclose. effective with less complications and recovery time [2]. A transobturator approach was introduced in 2001 [3]. To date there have been no larger series comparing the Sparc $^{\mathrm{TM}}$ (American Medical Systems, Minnetonka, MN) and Monarc ${ }^{\mathrm{TM}}$ (American Medical Systems, Minnetonka, MN) sling procedures. This paper aims to evaluate the effectiveness and complications of these two types of suburethral sling.

\section{MATERIALS AND METHODS}

A retrospective comparative series comparing 113 consecutive Sparcsuburethral slings with 112 consecutive Monarc slings from 2002 to 2012. The author changed to Monarc slings in 2006 as early studies had suggested a lower incidence of complications.

All patients were evaluated with history, examination, bladder diary, visual analogue scale (VAS) of subjective urinary incontinence bother and urodynamics. Included in this study were women who only had urodynamic stress incontinence (with no voiding difficulty or reduced bladder capacity), and did not need other surgery, such as prolapse surgery.

All surgeries were performed by the author, or under his direct supervision of registrars. Both procedures were performed under general anaesthesia. Tension was corrected so that no leakage was demonstrated with suprapubic pressure with the bladder filled to $300 \mathrm{ml}$.

The retropubic Sparc sling was inserted via two $5 \mathrm{~mm}$ suprapubic incisions and one $10 \mathrm{~mm}$ anterior suburethral vaginal incision using the Sparc introducers. Check cystscopy was performed, and the patient discharged upon voiding with a residual of less than $100 \mathrm{mls}$ on bladder scan.

The obturator Monarc sling was inserted via two $5 \mathrm{~mm}$ labial incisions and one $10 \mathrm{~mm}$ anterior suburethral vaginal incision using the Monarc introducers. Check cystoscopy was performed, and the patient discharged upon voiding with a residual of less than $100 \mathrm{mls}$ on bladder 
scan.

Follow up was at 6 weeks and 6 months by the author. Evaluation at these visits was by examination with a full bladder, history of any urinary symptoms (incontinence, urgency, voiding difficulty), VAS and bladder diary. Statistical analysis was performed using student $T$ test and Chi squares with significance reported if $P<0.05$. Success was defined as no stress incontinence seen at examination and no leaks/wk on bladder diary.

As this review conforms to the standards established by the NHMRC for ethical quality review ethics approval was not sought.

\section{RESULTS}

There were no significant demographical differences between the two groups (Table 1). Hospital discharge \& recovery times were quicker for the Monarc group (Table 2). The bladder fenestration rate was significantly higher in the Sparc group (Table 3). At six weeks both groups had a significant improvement in urinary incontinence (Table 4) with the Monarc group having less urgency. This difference was no longer significant at 6 months with both groups having a similar success rate (96\% vs 92.6\%) (Table 5). The five cases of voiding difficulty were managed with an overnight catheter and did not need repeat surgery.

\section{DISCUSSION}

This current study found a significant improvement is urinary incontinence in both groups at six weeks and six months. There was a slightly better success rate of the Monarc sling at 6 weeks, however at 6 months this was no longer statistically significant. The significant improvement in urinary incontinence was also seen in the VAS scores at six weeks and six months. There were two main differencesbetween the slings. The first was an increased bladder perforation rate for the Sparc procedure (17.2\% vs $0.9 \%, P=0.001)$. These were successfully treated by repositioning of the trochar with no long termsequelae. The second was an increased rate of urgency at 6 weeks for the Sparc sling ( $21.7 \%$ vs $8.8 \%, P=0.009$ ). This was no longer statistically significant at 6 months, although was still increased over the Monarc procedure $(19.8 \%$ vs $10.8 \%)$. There were no episodes of groin pain in either group over the six months of follow up. The incadence of voiding difficulty was low (2\%) in both groups. There was one incidence of mesh erosion in each group that was treated with re-epithelisation as day surgery.

The similar success rates at six months for Monarc \& Sparc $(96.0 \%$ vs $92.6 \%)$ in this study differs from a recently published systemic review in 2010 [4] which analysed 39 randomised controlled trials of female inconti-
Table 1. Baseline demographics (mean and standard deviation).

\begin{tabular}{cccc}
\hline & Monarc $(n=112)$ & Sparc $(n=113)$ & $P$ \\
\hline Age & $54.55[11.33]$ & $55.77[11.88]$ & NS \\
Weight & $75.34[14.67]$ & $76.62[16.43]$ & NS \\
Parity & $2.62[1.43]$ & $2.62[1.36]$ & NS \\
VH/TAH & $36.6 \%$ & $36.5 \%$ & NS \\
Leaks/wk & $9.73[9.25]$ & $10.35[8.61]$ & NS \\
Total voids/day & $10.33[8.9]$ & $11.33[9.1]$ & NS \\
VAS (/10) & $5.94[2.1]$ & $5.9[1.6]$ & NS \\
\hline
\end{tabular}

Table 2. Surgery (mean and standard deviation).

\begin{tabular}{cccc}
\hline & Monarc $(n=112)$ & Sparc $(n=113)$ & $P$ \\
\hline Time & $24.42[5.80]$ & $27.35[5.54]$ & NS \\
EBL & $87.6[38.5]$ & $80.75[30.87]$ & NS \\
Hospital & $1.04[1.13]$ & $1.63[1.33]$ & 0.0002 \\
Recovery & $3.07[1.31]$ & $3.48[1.49]$ & 0.02 \\
\hline
\end{tabular}

Table 3. Complications.

\begin{tabular}{cccc}
\hline & Monarc $(n=112)$ & Sparc $(n=113)$ & $\mathrm{P}$ \\
\hline Voiding Difficulty & $3(2.7 \%)$ & $2(1.8 \%)$ & NS \\
Bladder fenestration & $1(0.9 \%)$ & $23(17.2 \%)$ & 0.001 \\
\hline
\end{tabular}

Table 4. Six week complications (mean and standard deviation).

\begin{tabular}{cccc}
\hline & Monarc $(n=102)$ & Sparc $(n=105)$ & $P$ \\
\hline Leaks/wk & $0.75[2.85]^{1}$ & $1.77[5.54]^{2}$ & 0.05 \\
Total voids/day & $7.92[1.28]^{3}$ & $7.79[1.81]^{4}$ & NS \\
6 week success & $98(96.1 \%)$ & $99(94.3 \%)$ & NS \\
6 week urgency & $9(8.8 \%)$ & $26(21.7 \%)$ & 0.009 \\
6 week UTIs & 2 & 4 & NS \\
VAS (/10) & $0.5[1.3]^{5}$ & $0.7[1.6]^{6}$ & NS \\
\hline
\end{tabular}

${ }^{1}$ Change from baseline leakage $P=0.0001 ;{ }^{2}$ Change from baseline leakage $P=0.0001 ;{ }^{3}$ Change from baseline voids/day $P=0.004 ;{ }^{4}$ Change from baseline voids/day $P=0.0001$; ${ }^{5}$ Change from baseline VAS $P=0.0001$; ${ }^{6}$ Change from baseline VAS $P=0.0001$.

nence procedures. Midurethral tapes had a higher cure rate than Burch colposuspension. Comparing retropubic and transobturator tapes, the former had a slightly higher objective cure rate, with a much higher risk of bladder perforation and voiding difficulty.

A Cochrane review [5] examined 62 trials of synthetic slings and concluded that the obturator route had a less favourable objective cure ( $84 \%$ vs $88 \%$ ), however with 
Table 4. Six month complications (mean and standard deviation).

\begin{tabular}{cccc}
\hline & Monarc $(n=74)$ & Sparc $(n=81)$ & $P$ \\
\hline Leaks/wk & $0.82[3.65]$ & $1.55[4.0]$ & NS \\
Total voids/day & $7.60[1.4]$ & $7.65[1.9]$ & NS \\
6 month success & $71(96.0 \%)$ & $75(92.6 \%)$ & NS \\
6 month urgency & $8(10.8 \%)$ & $16(19.8 \%)$ & NS \\
6 month UTIs & 1 & 1 & NS \\
VAS (/10) & $0.7[1.4]$ & $0.9[1.8]$ & NS \\
Mesh Erosion & 1 & 1 & NS \\
\hline
\end{tabular}

less voiding dysfunction (4\% vs $7 \%$ ) and bladder perforation $(0.3 \%$ vs $5.5 \%)$.

The higher bladder perforation rate in this study has also been reported in other retropubic series (2\% - 13\%) [6-10]. Other complications reported include urinary retention (1\% - 20\%), urinary infections $(1 \%-22 \%)$ \& de novo urgency $(2 \%-25 \%)$. The voiding difficulty rate was low in this current study for both groups.

A literature review found that Monarc has not been commonly compared to Sparc.

In 2005 [11] a prospective randomised trial of 60 patients compared Sparc and Monarc slings, and reported similar success rates at a mean follow up of 9 months.

Kim [12] conducted a prospective randomised trial of SPARC $(n=22)$ and Monarc $(n=21)$ surgeries, and reported similar short term cures rates ( $81.8 \%$ vs $80.9 \%)$

Botros [13] retrospectively compared Monarc $(n=$ $125)$, Sparc $(n=52)$, and TVT $(n=99)$ slings and reported at 3 months the Monarc group had significantly less detrusor overactivity symptoms ( $8 \%$ vs $17 \%$ Sparcvs $33 \%$ TVT). This finding is similar to this present study.

Rapp [14] compared Monarc $(n=39)$ with Sparc $(n=$ 97) slings retrospectively over 36 months for the treatment of intrinsic sphincter deficiency and found similar success rates $(77 \%$ vs $76 \%)$. The lower success, compared to the current study, relates to the more difficult to treat intrinsic deficiency. The complication rate also was lower in the Monarc group (3\% vs 7\%), however this did not reach statistical significance.

Other reported series may use TVT or TVT-O by way of comparison. In particular the TVT-O group, using the in-out approach, had a higher reported incidence of groin pain however with a lower incidence of bladder perforation, urgency \& voiding difficulty [15-19]. The lack of groin pain in this current study, particularly relating to the Monarc group, may be due to the out-in approach with a more precise placement of the trochar in the medial obturator canal that avoids the lateral neurovascular vessels.
Richter [20] performed a large randomised multicentre trial of 597 women with stress urinary incontinence, comparing retropubic TVT $(n=298)$ versus transobturator TVT-O or Monarc ( $n=299$ of which 137 had Monarc) midurethral slings with 12 month follow up. There was a similar objective cure rate ( $80.8 \%$ vs $77.7 \%)$, whilst the retropubic group had significantly more intraoperative bladder perforations ( $5 \%$ vs $0 \%$ ) and higher voiding dysfunction $(2.7 \%$ vs $0 \%)$. Overall the retropubic had significantly more serious adverse events ( $13.8 \%$ vs $6.4 \%)$. However groin pain was significantly increased in the obturator group (9.4\% vs 4.0 ), as was vaginal perforations ( $4.3 \%$ vs $2.0 \%)$. Of interest was that most occurred in the in-out TVT-O group. This large study can be study can be criticised because there were multiple surgeons (43) and that there were two obturator approaches that were not randomised.

This current series is the largest reported series to compare Monarc with Sparcsuburethal slings for the treatment of stressurinary incontinence, and finds a similar success rate between the Monarc \& Sparc at 6 months (96\% vs $92.6 \%$ ), with less intraoperative complications and a trend towards less post operative complications in the Monarc group. Limitations of the study are that the author was not blinded at follow up as to which form of sling was performed. Another limitation is that the groups were historically controlled, with Sparc being performed from 2002-2006 \& Monarc from 2006-2010. A learning curve effect could have resulted in the Monarc having a better success rate. A counter to this argument is that the author performed over 100 TVT retropubic slings before Sparc was available.

\section{CONCLUSION}

In conclusion, both procedures had a similar success rate, while the Monarc had fewer complications of intraoperative bladder fenestration \& postoperative urgency, with no reported cases of groin pain.

\section{REFERENCES}

[1] Ulmsten, U. and Petros, P. (1995) Intravaginalslingplasty (IVS). An ambulatory surgical procedure for treatment of female urinary incontinence. Scandinavian Journal of Urology and Nephrology, 29, 75-82. http://dx.doi.org/10.3109/00365599509180543

[2] Ward, K.L. and Hilton, P. (2004) A prospective multicentre randomised trial of tension-free vaginal tape and colposuspension for primary urodynamic stress incontinence. American Journal of Obstetrics \& Gynecology, 190, 324-331. http://dx.doi.org/10.1016/j.ajog.2003.07.029

[3] Delorme E. (2001) Transobturator urethral suspension. Mini-invasive procedure in the treatment of stress urinary 
incontinence. Progres en Urologie, 11, 1306-1313

[4] Novara, G., Artibani, W., Barber, M.D., et al. (2010) Updated systemic review and meta-analysis of the comparative data on colposuspensions, pubovaginal slings, and midurethral slings in the surgical treatment of female stress urinary incontinence. European Urology, 58, 218238. http://dx.doi.org/10.1016/j.eururo.2010.04.022

[5] Ogah J, Cody DJ, Rogerson L. (2011) Minimally invasive systheticsuburethral sling operations for stress urinary incontienence: A short version Cochrane review. Neurourology and Urodynamics, 30, 284-291. http://dx.doi.org/10.1002/nau.20980

[6] SchraffordtKoops, S., Bisseling, T., Heintz, A., et al. (2005) Prospective analysis of complications of tension free vaginal tape from the Netherlands tension free vaginal tape study. American Journal of Obstetrics \& Gynecology, 193, 45-53.

http://dx.doi.org/10.1016/j.ajog.2004.11.004

[7] Abouassaly, R., Jordan, R., Steinberg, R., et al. (2004) Complications of tension free vaginal tape surgery: A multi-institutional review. BJU International, 94, 110113.

http://dx.doi.org/10.1111/j.1464-410X.2004.04910.x

[8] Nilsson, C. and Kuuva, N. (2001) The tension free vaginal tape procedure is successful in the majority of women with indications for surgical treatment of urinary stress incontinence. BJOG, 108, 414-419. http://dx.doi.org/10.1111/j.1471-0528.2001.00092.x

[9] Niknejad, K., Plzak, L., Staskin, D., et al. (2002) Autologous and synthetic urethral slings for female incontinence. Urologic Clinics of North America, 29, 597-611. http://dx.doi.org/10.1016/S0094-0143(02)00074-5

[10] Latthe, P.M., Foon, R. and Toozs-Hobson, P. (2007) Transobturator and retropubic tape procedures in stress urinary incontinence: A systematic review and metaanalysis of effectiveness and complications. BJOG, 114, 522-531. http://dx.doi.org/10.1111/j.1471-0528.2007.01268.x

[11] Wang, A.C., Lin, Y.H., Tseng, L.H., et al. (2006) Prospective randomised comparison of transobturatorsuburethral sling (Monarc) vssuprapubic arc (Sparc) sling procedures for female urodynamic stress incontinence. International Urogynecology Journal and Pelvic Floor Dysfunction, 17, 439-443. http://dx.doi.org/10.1007/s00192-005-0035-0
[12] Kim, Y., Na, Y. and Sul, C. (2005) Randomised prospective study between pubovaginal sling using SPARC sling system and MONARC sling system for the treatment of female stress urinary incontinence: Short term results. Korean Journal of Urology, 46, 1078-1082.

[13] Botros, S.M., Miller, J.R., Goldberg, R.P., et al. (2007) Detrusor overactivity and urge urinary incontinence following transobturator versus midurethral slings. Neurourology and Urodynamics, 26, 42-45. http://dx.doi.org/10.1002/nau.20377

[14] Rapp, D.E., Govier, F.E. and Kobashi, K.C. (2009) Outcomes following mid-urethral sling placement in patients with intrinsic sphincter deficiency: Comparison of Sparc withMonarc slings. International Brazilian Journal of Urology, 35, 68-75. http://dx.doi.org/10.1590/S1677-55382009000100011

[15] Rinne, K., Laurikainen, E., Kivela, A. et al. (2008) A randomised trial comparing TVT with TVT-O: 12 month results. International Urogynecology Journal, 19, 10491054

[16] Araco, F., Gravante, G., Sorge, R., et al. (2008) TVT-O vs TVT: A randomized trial in patients with different degrees of urinary stress incontinence. International Urogynecology Journal, 19, 917-926. http://dx.doi.org/10.1007/s00192-007-0554-y

[17] Liapis, A., Bakas, P., Giner, M. and Creatsas, G. (2006) Tension-free vaginal tape versus tension-free vaginal tape obturator in women with stress urinary incontinence. Gynecologic \& Obstetric Investigation, 62, 160-164. http://dx.doi.org/10.1159/000093320

[18] Ross, S., Robert, M., Swaby, C., et al. (2009) Transobturator tape compared with tension-free vaginal tape for stress incontinence: A randomized controlled trial. $\mathrm{Ob}$ stetrics \& Gynecology, 114, 1287-1294. http://dx.doi.org/10.1097/AOG.0b013e3181c2a151

[19] George, S., Begum, R., Thomas-Philip, A., et al. (2010) Two-year comparison of tension-free vaginal tape and transobturator tape for female urinary stress incontinence. Journal of Obstetrics \& Gynaecology, 30, 281-284. http://dx.doi.org/10.3109/01443610903551756

[20] Richter, H.E., Albo, M.E., Zyczynski, H.M. et al. (2010) Retropubic versus transobturator midurethral slings for stress incontinence. The New England Journal of Medicine, 362, 2066-2076. http://dx.doi.org/10.1056/NEJMoa0912658 